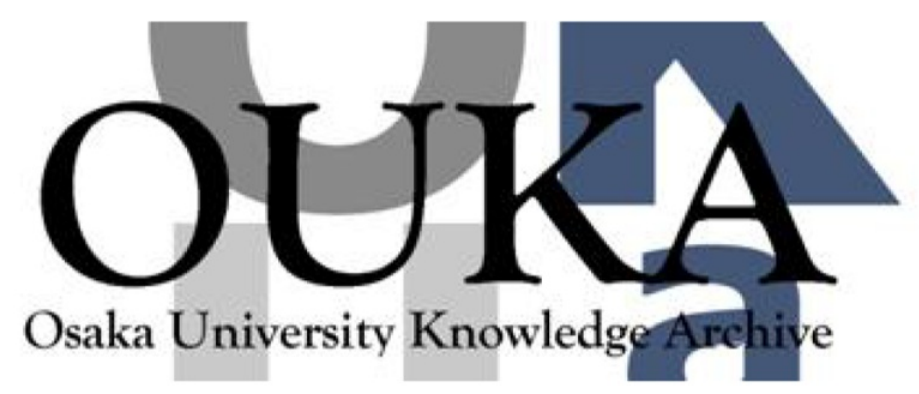

\begin{tabular}{|c|l|}
\hline Title & $\begin{array}{l}\text { Numerical Model with Arc Length Variation of } \\
\text { Welding Arc with Constant Voltage Power Source }\end{array}$ \\
\hline Author(s) & $\begin{array}{l}\text { Tashiro, Shinichi; Tsujimura, Yoshihiro; } \\
\text { Tanaka, Manabu }\end{array}$ \\
\hline Citation & Transactions of JWRI. 41(1) p.7-p. 10 \\
\hline Issue Date & $2012-06$ \\
\hline oaire:version VoR \\
\hline URL & https://doi.org/10.18910/23157 \\
\hline rights & \\
\hline Note & \\
\hline
\end{tabular}

Osaka University Knowledge Archive : OUKA

https://ir. Library. osaka-u. ac. jp/

Osaka University 


\title{
Numerical Model with Arc Length Variation of Welding Arc with Constant Voltage Power Source ${ }^{\dagger}$
}

\author{
TASHISRO Shinichi*, TSUJIMURA Yoshihiro**, TANAKA Manabu***
}

\begin{abstract}
In the present paper, Tungsten Inert Gas (TIG) arc with Constant Voltage (CV) power source is modeled if arc length changes. And TIG arc with Constant Current (CC) power source is also modeled if arc length changes. The TIG arc is assumed on base material of water-cooled copper. For the CV power source, Maximum temperature of arc plasma and arc current increase with decrease of arc length. For the CC power source, arc voltage changes but maximum temperatures of arc plasma is almost constant in spite of change of arc length. Arc power increases with decrease of arc length for the CV power source. On the other hand, arc power decrease with decrease of arc length for the CC power source. For the CV power source, arc power changes largely if arc length changes. However, for the CC power source, arc power changes little if arc length changes. Heat input from welding power source more stable using a CC power source than a CV power source at TIG welding with a change of arc length.
\end{abstract}

KEY WORDS: (Simulation), (Arc), (TIG), (Power source)

\section{Introduction}

There are constant current (CC) power source and constant voltage $(\mathrm{CV})$ power source in welding power source. A CC power source supplies electric current stably. A CV power source supplies the self-adjusting of arc length for consumable electrode arc welding like a MIG/MAG ${ }^{1,2)}$. In MAG welding, arc length changes by wire feeding and metal transfer. As arc length changes, arc current changes to keep arc voltage constant for a CV power source. A stability of arc current depends on the characteristics of power sources. Arc current has a big influence on arc welding process ${ }^{1)}$. During the arc welding process, four states of matter, solid, liquid, gas and plasma, simultaneously exist and mutually interact ${ }^{3}$. Such complex arc phenomena are affected by conditions, like an arc length, an arc current, a characteristic of power source, a gas composition and so on ${ }^{1,2,4-6)}$. Aim of this study is to understand effects of power source characteristics, like a CC power source or a CV power source, on arc phenomena when dynamic change arises, like a time-dependence of arc length. Simulation technology is helpful to understand such phenomena ${ }^{7}$. There are many reports that performed numerical analysis of gas metal arc (GMA) welding or tungsten inert gas (TIG)

\footnotetext{
$\dagger$ Received on June 18, 2012

* Assistant professor

** Graduate Student

*** Professor
}

welding 8, 9). These models only have CC characteristics. In this study, TIG arc with CV power source is modeled if arc length changes at artificially controlled frequency. And TIG arc with CC power source is also modeled if arc length changes. We assume TIG arc on a base material of water-cooled copper at atmosphere pressure in argon.

\section{Simulation model}

The tungsten cathode, the arc plasma and the water-cooled copper anode are described relative to cylindrical coordinates, assuming rotational symmetry around the arc axis. The calculation domain is shown in Fig. 1. The diameter of the tungsten cathode is 3.2 $\mathrm{mm}$ with a 60 degrees conical tip. The time-dependence of arc length is shown in Fig. 2. In this model, number of mesh is constant. However, mesh size changes if arc length changes. For the CV power source, the arc voltage is set to be a $10 \mathrm{~V}$. For the CC power source, the arc current is set to be a 150 A. Argon shielding gas is introduced from the outside of the cathode on the upper boundary at the flow rate of $10 \mathrm{~L} / \mathrm{min}$. The flow is assumed to be a laminar flow, and the arc plasma is assumed to be under the Local Thermodynamic Equilibrium (LTE).

Transactions of JWRI is published by Joining and Welding Research Institute, Osaka University, Ibaraki, Osaka 567-0047, Japan 


\section{Numerical Model with Arc Length Variation of Welding Arc with Constant Voltage Power Source}

For the CV power source, a temporary arc current is firstly set and then the temporary arc current is modified till an output arc voltage becomes $10 \mathrm{~V}$ under the implicit iterative calculation.

We conduct the time dependent two-dimensional calculations. The governing equations used in the model are shown as follows:

The mass continuity equation is,

$\frac{\partial \rho}{\partial t}+\frac{1}{r} \frac{\partial}{\partial r}\left(r \rho v_{r}\right)+\frac{\partial}{\partial z}\left(\rho v_{z}\right)=0$

The radial momentum conservation equation is,

$\frac{\partial \rho v_{r}}{\partial t}+\frac{1}{r} \frac{\partial}{\partial r}\left(r \rho v_{r}^{2}\right)+\frac{\partial}{\partial z}\left(\rho v_{z} v_{r}\right)=$

$-\frac{\partial p}{\partial r}-j_{z} B_{\theta}+\frac{1}{r} \frac{\partial}{\partial r}\left(2 r \eta \frac{\partial v_{r}}{\partial r}\right)+\frac{\partial}{\partial z}\left(\eta \frac{\partial v_{r}}{\partial z}+\eta \frac{\partial v_{z}}{\partial r}\right)-2 \eta \frac{v_{r}}{r^{2}}$

The axial momentum conservation equation is,

$\frac{\partial \rho v_{z}}{\partial t}+\frac{1}{r} \frac{\partial}{\partial r}\left(r \rho v_{r} v_{z}\right)+\frac{\partial}{\partial z}\left(\rho v_{z}^{2}\right)=$

$-\frac{\partial p}{\partial z}-j_{r} B_{\theta}+\frac{\partial}{\partial z}\left(2 \eta \frac{\partial v_{z}}{\partial z}\right)+\frac{1}{r} \frac{\partial}{\partial r}\left(r \eta \frac{\partial v_{r}}{\partial z}+r \eta \frac{\partial v_{z}}{\partial r}\right)+\rho g$

The energy conservation equation is,

$\frac{\partial \rho h}{\partial t}+\frac{1}{r} \frac{\partial}{\partial r}\left(r \rho v_{r} h\right)+\frac{\partial}{\partial z}\left(\rho v_{z} h\right)=$

$\frac{1}{r} \frac{\partial}{\partial r}\left(\frac{r \kappa}{c_{p}} \frac{\partial h}{\partial r}\right)+\frac{\partial}{\partial z}\left(\frac{\kappa}{c_{p}} \frac{\partial h}{\partial z}\right)+j_{r} E_{r}+j_{z} E_{z}-U$

The current continuity equation is,

$\frac{1}{r} \frac{\partial}{\partial r}\left(r j_{r}\right)+\frac{\partial}{\partial z}\left(j_{z}\right)=0$

$j_{r}=\sigma E_{r}, j_{z}=\sigma E_{z}$

where, $t$ is time, $h$ is enthalpy, $p$ is pressure, $v_{r}$ and $v_{z}$ are radial and axial velocities, $j_{r}$ and $j_{z}$ are the radial and axial components of the current density, $g$ is acceleration due to gravity, $c_{p}$ is specific heat, $\kappa$ is thermal conductivity, $\rho$ is density, $\eta$ is viscosity, $U$ is radiative emission coefficient, and $\sigma$ is electrical conductivity. $E_{r}$ and $E_{z}$ are the radial and axial components of the electric field defined by:

$E_{r}=-\frac{\partial V}{\partial r} \quad E_{z}=-\frac{\partial V}{\partial z}$

where, $V$ is electric potential.

The azimuthal magnetic field, $B_{\theta}$ induced by arc current is evaluated by Maxwell's equation:

$\frac{1}{r} \frac{\partial}{\partial r}\left(r B_{\theta}\right)=\mu_{0} j_{z}$

where, $\mu_{0}$ is the permeability of free space.

It is necessary to consider the effects of energy transfer at the electrode surfaces. The additional energy fluxes at the cathode and anode are described as:

Cathode : $F_{K}=-\varepsilon \alpha T^{4}-\left|j_{e}\right| \phi_{K}+\left|j_{i}\right| V_{i}$
Anode : $F_{A}=-\varepsilon \alpha T^{4}+|j| \phi_{A}$

where, $\varepsilon$ is surface emissivity, $\alpha$ is the

Stefan-Boltzmann constant, $\phi_{K}$ is the work function of the tungsten cathode, $V_{i}$ is the ionization potential of the plasma gas, $j_{e}$ is the electron current density, $j_{i}$ is the ion current density, $\phi_{A}$ is the work function of the anode and $T$ is the temperature. For the cathode surface, $F_{K}$ needs to be included in Equation (4) to take into account the thermionic cooling by emission of electrons, radiative cooling and ion heating. Similarly, for the anode surface, $F_{A}$ is required in Equation (4) to take into account radiative cooling and thermionic heating. Furthermore, for the cathode surface, the electron current and the ion current are considered separately and defined based on the Richardson-Dushman equation of thermionic emission as follows:

$j_{R}=A T^{2} \exp \left(-\frac{e \phi_{K}}{k_{B} T}\right)$

where, $k_{B}$ is the Boltzmann's constant and $A$ is the Richardson's constant, which depend on the cathode material. The ion current density, $j_{i}$ is then assumed to be $j_{i}=j-j_{R}$, where the total current density, $j$ is $|j|=\left|j_{e}\right|+\left|j_{i}\right|$.

The gas properties are referred from 5). And the electrodes properties are given in 10). The other approximations, governing equations and boundary conditions are given in detail in our previous papers ${ }^{6}$, $11,12)$.

\section{Results and discussion}

Figures 3 and 4 show calculated results of temperature fields for the $\mathrm{CV}$ power source and the $\mathrm{CC}$ power source at $0.15 \mathrm{~s}$ and $0.2 \mathrm{~s}$ after arc ignitions. For the $\mathrm{CV}$ power source, the maximum temperature of arc plasma is $18000 \mathrm{~K}$ for $5 \mathrm{~mm}$ in arc length and the maximum temperature of arc plasma is $23000 \mathrm{~K}$ for 3 $\mathrm{mm}$. For the $\mathrm{CC}$ power source, the maximum temperature of arc plasma is constantly $19000 \mathrm{~K}$ even if the arc length changes.

Figure 5 shows calculated results of time-dependence of arc current with arc length for the $\mathrm{CV}$ power source. The arc current is $130 \mathrm{~A}$ for $5 \mathrm{~mm}$ in arc length and the arc current is $200 \mathrm{~A}$ for $3 \mathrm{~mm}$.

Figure 6 shows calculated results of time-dependence of arc voltage with arc length for the $\mathrm{CC}$ power source. The arc voltage is $10.5 \mathrm{~V}$ for $5 \mathrm{~mm}$ in arc length and the arc voltage is $9.1 \mathrm{~V}$ for $3 \mathrm{~mm}$.

Figure 7 shows calculated result of time-dependence of arc power with arc length for the $\mathrm{CV}$ power source and the $\mathrm{CC}$ power source. In this figure, arc power increase with decrease of arc length 
for the $\mathrm{CV}$ power source. Because arc current increase with decrease of arc length. On the other hand, arc power decrease with decrease of arc length for the CC power source. Because arc voltage decrease of arc length. For the CV power source, arc power is $1300 \mathrm{~W}$ for $5 \mathrm{~mm}$ in arc length and arc power is $2000 \mathrm{~W}$ for 3 $\mathrm{mm}$. For the CC power source, arc power is $1600 \mathrm{~K}$ for $5 \mathrm{~mm}$ in arc length and arc power is $1400 \mathrm{~K}$ for $3 \mathrm{~mm}$. For the $\mathrm{CV}$ power source, arc power changes largely if arc length changes. However, for the $\mathrm{CC}$ power source, arc power changes little if arc length changes. From this, heat input from welding power source more stable using a $\mathrm{CC}$ power source than a $\mathrm{CV}$ power source at TIG welding with a change of arc length.

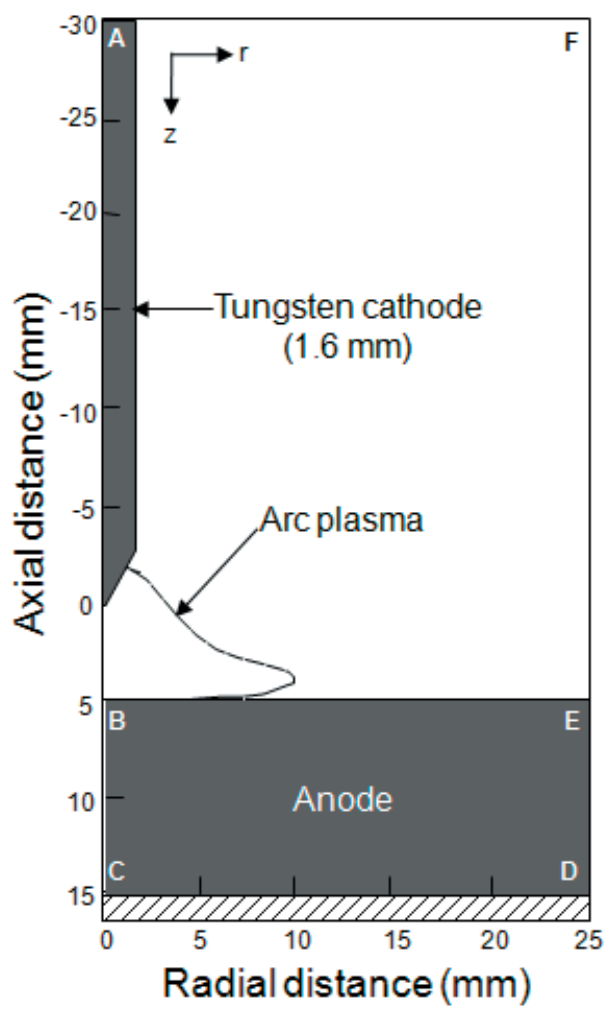

Fig. 1 Schematic illustration of simulation domain

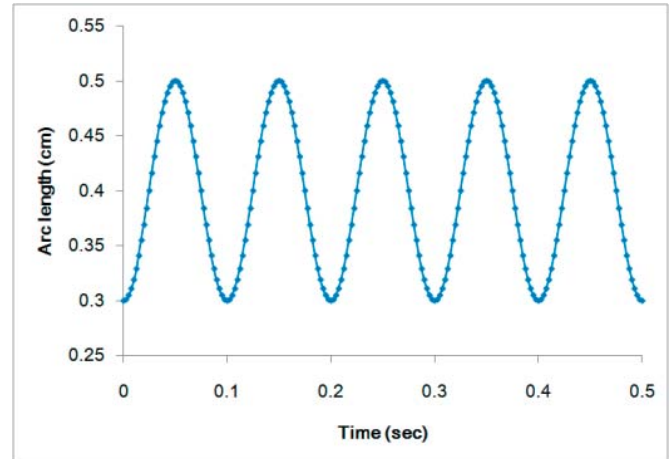

Fig. 2 Assumption of time-dependence of arc length at $10 \mathrm{~Hz}$

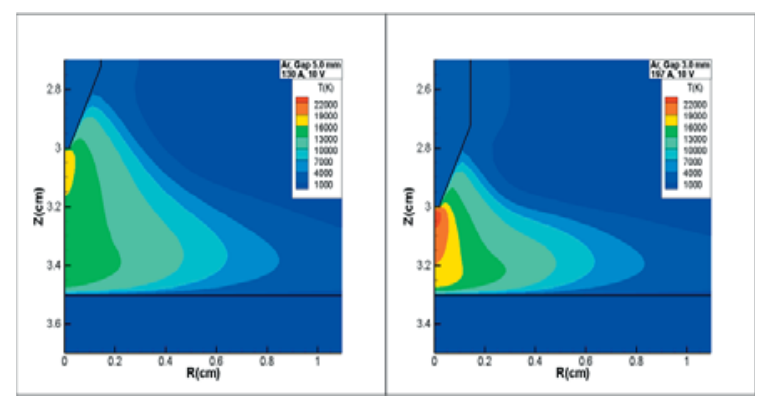

(a) $\mathrm{t}=0.15 \mathrm{~s}$ (Arc length : $5 \mathrm{~mm}$ ) (b) $\mathrm{t}=0.2$ $\mathrm{s}$ (Arc lenath : $\mathbf{3} \mathrm{mm}$ )

Fig. 3 Calculated results of temperature field for the $\mathrm{CV}$ power source

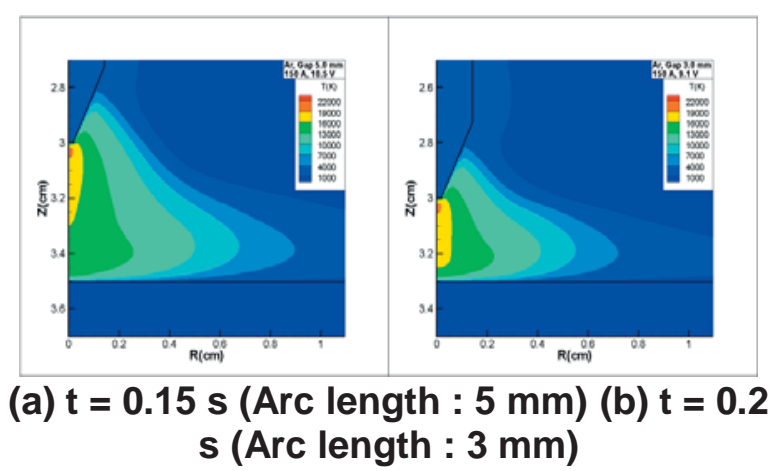

Fig. 4 Calculated results of temperature field for the $\mathrm{CC}$ power source

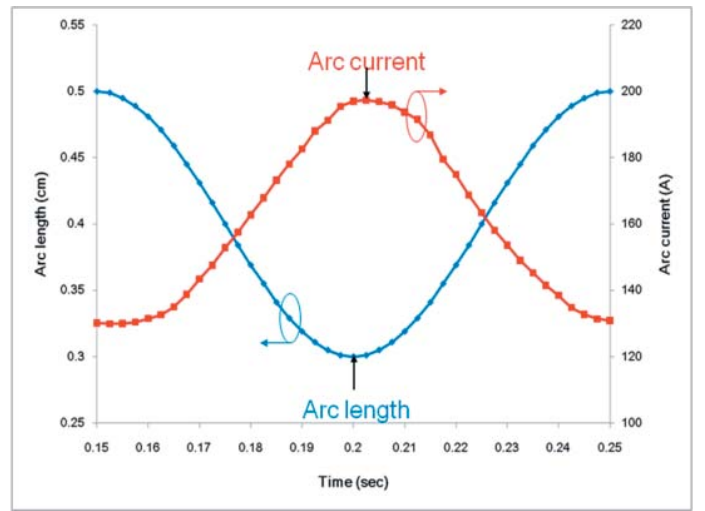

Fig. 5 Calculated result of time-dependence of arc current with arc length for the $\mathrm{CV}$ power source 


\section{Numerical Model with Arc Length Variation of Welding Arc with Constant Voltage Power Source}

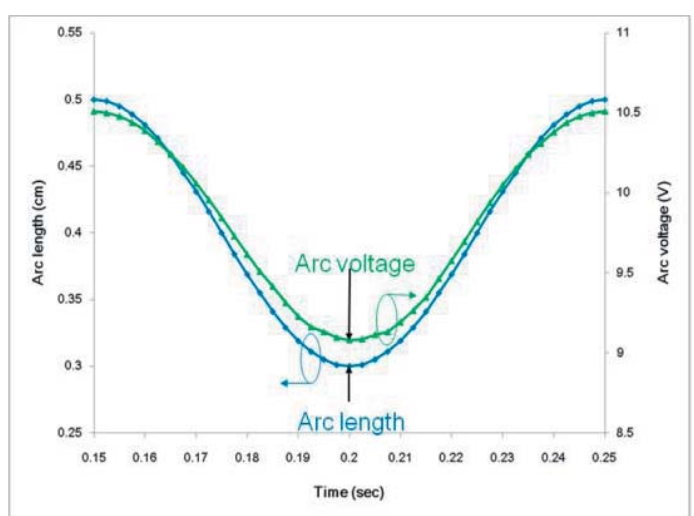

Fig. 6 Calculated result of time-dependence of arc voltage with arc length for the $\mathrm{CC}$ power source

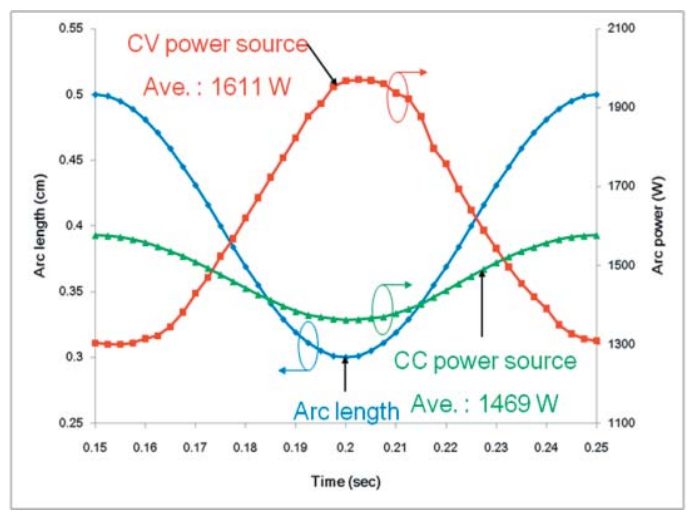

Fig. 7 Calculated result of time-dependence of arc power with arc length

\section{Conclusions}

Main conclusions are summarized as follows:

(1) TIG arcs with a CV power source and with a CC power source are modeled when arc length changes from $3.0 \mathrm{~mm}$ to $5.0 \mathrm{~mm}$ at $10 \mathrm{~Hz}$.

(2) Maximum temperature of arc plasma and arc current increase with decrease of arc length for the CV power source.

(3) For the CC power source, arc voltage changes but maximum temperatures of arc plasma is almost constant in spite of change of arc length.

(4) Arc power increase with decrease of arc length for the $\mathrm{CV}$ power source. On the other hand, arc power decrease with decrease of arc length for the $\mathrm{CC}$ power source.

(5) For the CV power source, arc power changes largely if arc length changes. However, for the CC power source, arc power changes little if arc length changes.

\section{References}

1) T. Ouji: Introduction of Welding Processes, First edition (1996), SANPO PUBLICATIONS, INC (in Japanese)

2) Japan Welding Society: Technology of Welding and Joining (2005), SANPO PUBLICATION, INC (in Japanese)

3) M. Tanaka, T. Watanabe, T. Isa and H. Nishikawa: New development of welding and thermal spraying, J. Plasma \& Fusion Res., 82-8 (2006), 492-496 (in Japanese).

4) M. Tanaka, S. Tashiro, S. Satoh, A.B. Murphy and J.J. Lowke: Influence of shielding gas composition on arc properties in TIG welding, Science and Technology of Welding \& Joining, Volume 13, Number 3, April 2008 , pp. 225-231(7)

5) A.B. Murphy, M. Tanaka, S. Tashiro, T. Sato and J.J. Lowke: A computational investigation of the effectiveness of different shielding gas mixtures for arc welding, J.Phys.D:Appl.Phys.42(2009),115205(14pp)

6) K. Yamamoto, M. Tanaka, S. Tashiro, K. Nakata, K. Tamazaki, E. Yamamoto, K. Suzuki and A.B. Murphy: Metal vapour behaviour in thermal plasma of gas tungsten arcs during welding, Science and Technology of Welding \& Joining, Volume 13, Number 6, September 2008 , pp. 566-572(7)

7) M. Tanaka and J.J. Lowke: Predictions of weld pool profiles using plasma physics, J.Phys.D:Appl.Phys.40(2007),R1-R23

8) H.G. Fan and R. Kovacevic: The front line of modeling heat and mass transfer in arc welding processes, J. Japan Welding Soc., 76-2 (2007), 82-89.

9) H. Nishiyama, T. Sawada, H. Takana, M. Tanaka and M. Ushio: Computational simulation of arc melting process with complex interactions, ISIJ Int., $46-5$ (2006), 705-711.

10) The Japan Institute of Metals, Edition No. 3 Data Book of Metals, MARUZEN CO., LTD, 1993 (in Japanese)

11) S. Tashiro, et al: Plasma properties of helium gas tungsten arc with metal vapor, Quarterly J. Japan Welding Soc., 24-2 (2006), 143-148 (in Japanese).

12) S. Tashiro, et al: Properties of Mass and Heat Transfer for Tube Cathode Arcs, Quarterly J. Japan Welding Soc., 25-1 (2007), 3-9 (in Japanese). 